\title{
UM ESTUDO SOBRE REDUÇÃO DO ESTADO DE ANSIEDADE ATRAVÉS DE DINÂMICA DE GRUPO *
}

\author{
Marilene Schmarczek ${ }^{* *}$
}

SCHMARCZEK, $M$. Um estudo sobre redução do estado de ansiedade através de dinâmica de grupo. Rev. Esc. Enf. USP, São Paulo, 20(3):207-217, 1986.

Estuda-se a ansiedade-estado de um grupo de enfermeiras pedidtricas que se reuniram para discutir suas preocupaçoes de trabalho. A ansiedade-estado, verificada através da aplicação de Inventário de Ansiedade Traço-Estado de SPIELBERGER, indicou redução significativa no estado de ansiedade no final das sessões de grupo.

\section{INTRODUÇAO}

A ansiedade tem sido tema de estudo nas áreas da biologia e psicologia. Uma vasta bibliografia é encontrada, mas como refere GRAY (1982), após um exaustivo estudo sobre neuropsicologia da ansiedade, "o trabalho serve como guia do que é ansiedade, só o tempo e a experiência falarão".

$\mathrm{Na}$ atualidade, entre outros autores, SPIELBERGER (1976) tem estudado o tema ansiedade e, nele identifica uma série de questões relacionadas à ansiedade em situações das mais diversas.

Na enfermagem, o tema vem sendo estudado internacionalmente, por vários autores, o que não ocorre no Brasil, onde são escassos esses estudos.

No presente trabalho, relata-se a experiência vivida por um grupo de enfermeiras que se reuniram para discutir os temas que as preocupavam. $O$ objetivo desses encontros foi reduzir a ansiedade que supostamente existia no grupo.

\section{Referencial teórico}

Fundamentou-se o estudo da ansiedade no referencial teórico proposto por SPIELBERGER (1981), que considera a ansiedade como estado e traço. A ansiedade-estado relaciona-se às reações emocionais caracterizadas por sentimentos conscientes e subjetivos de tensão, apreensão,

* Trabalho orientado e supervisionado pela DRA. ANGELA MARIA BRASIL BIAGGIO.

* Enfermeira. Docente da Escola de Enfermagem da UFrGS - disciplina Enfermagem em Sadde Mental - Palquiatria. 
nervosismo e preocupação, enquanto a ansiedade-traço corresponde à propensão à ansiedade, própria de cada indivíduo.

Na mesma obra, SPIELBERGER (1981) dedica dois capitulos à descrição de "como lidar com a ansiedade", seguidos do capitulo onde indica "como conviver com a tensão e a ansiedade". Para compreender os fatos vividos pelo grupo e, partindo da compreensão de que as enfermeiras convivem com situações de ansiedade, utilizou-se a referência de "como conviver com tensão e ansiedade". Ao abordar o tema, o autor chama a atenção para várias situações onde o individuo convive com ansiedade $e$ discute os aspectos positivos e negativos dessa convivência; estabelece cinco passos para se viver com tensão e ansiedade, quais sejam: 1) ter consciência da ansiedade como estado emocional; 2) observar quando o estado emocional ocorre; 3 ) perceber se as reações ao estado emocional são proporcionais aos perigos que as provocam; 4) examinar os recursos para enfrentar a ansiedade; 5) verificar o nível pessoal de propensão à ansiedade e as defesas psicológicas para a enfrentar.

Adaptou-se a mesma seqüência para a compreensão de outras emoções que surgiram no grupo e, durante o desenvolvimento do trabalho, os passos um e dois foram os mais trabalhados.

\section{METODOLOGIA}

\section{Características da amostra}

Foram sujeitos do estudo dez enfermeiras que trabalham em unidades pediátricas de um hospital geral.

$\mathrm{O}$ quadro a seguir indica: o ano de formatura das enfermeiras que integraram o grupo; a formação especializada e o tempo em que trabalham na instituição (especificamente na área).

QUADRO I

ANO DE GRADUAÇAO, FORMAÇAO ESPECIALIZADA, E TEMPO DE SEIRVIÇO NA AREA

\begin{tabular}{ccl}
$\begin{array}{c}\text { Ano de } \\
\text { Graducăo }\end{array}$ & $\begin{array}{c}\text { Formação em enfermagem } \\
\text { pedítrica }\end{array}$ & $\begin{array}{c}\text { Tempo de servico } \\
\text { (ma área) }\end{array}$ \\
\hline 82 & Educação Psicomotora & 3 anos e 8 meses \\
81 & Educação Psicomotora & 3 anos e 9 meses \\
81 & - & 2 anos e 6 meses \\
80 & - & 4 anos e 3 meses \\
80 & - & 1 ano e 6 meses \\
79 & - & 3 anos \\
78 & - & 4 anos \\
77 & Enfermagem Pediátrica e Puericultura & 6 anos \\
76 & Enfermagem Pediátrica e Puericultura & 8 anos \\
75 & Enfermagem Materno-Infantil & 5 anos \\
\hline
\end{tabular}


Para verificar a ansiedade existente no grupo foi aplicado o Inventário de Ansiedade Traço-Estado (IDATE), que se caracteriza por um questionário de auto-avaliação, publicado pelo Centro Editor de Psicologia Aplicada (CEPA), com direitos reservados e reprodução proibida. Para utilizá-lo é necessário um psicólogo responsável (para sua aquisição e aplicação). Na primeira página do inventário, identifica-se o respondente e são fornecidas instruções sobre o seu preenchimento. $O$ questionário é constituído por duas partes, ambas com vinte questões, que permitem quatro alternativas de avaliação. A primeira parte do questionário mede a ansiedade-estado e formula a questão: "Como você se sente neste momento?" - no caso, adaptou-se a questão a: "Como você se sente no seu trabalho?". As respostas às questões da Parte I correspondem aos valores: muitíssimo -4 ; bastante -3 ; um pouco -2 ; absolutamente não - 1 .

A segunda parte mede a ansiedade-traço e focaliza a questão: "Como você se sente geralmente?". A avaliação permite quatro alternativas às respostas que são: quase sempre - 4; freqüentemente -3 ; às vezes 2; quase nunca - 1. O IDATE (questionário) é calculado conforme as instruções do Manual de Psicologia Aplicada - Inventário de Ansiedadia Traço-Estado de SPIELBERGER, GORSUCH e LUSHENE - ambos publicados pelo CEPA traduzidos e adaptados para o português por BIAGGIO e NATALfCIO em 1979.

Os outros dados comentados na apresentação dos resultados foram colhidos durante as sessões de grupo (os temas tratados têm apresentado apenas a síntese dos conteúdos trabalhados) no início dos encontros ( a identificação das expectativas e as características das enfermeiras que integraram os grupos) e ao término dos encontros do grupo (considerações sobre a atividade - dinâmica do grupo - vivenciada).

\section{Procedimento}

O grupo foi organizado por solicitação de várias enfermeiras à assessora de Enfermagem Pediátrica da Instituição em que trabalham. Entre as enfermeiras que trabalham na área, nem todas estavam interessadas em participar da atividade.

As componentes do grupo encontravam-se sob a coordenação de uma enfermeira, com formação em trabalho com grupos.

No primeiro dia, compareceram doze enfermeiras, sendo que, posteriormente, uma não encontrou substituta no trabalho e outra entrou em licença para tratamento de saúde, deixando de integrar o grupo. Nesse encontro foi aplicado o IDATE (questionário de auto-avaliação) e feita coleta de alguns dados referentes ao trabalho das enfermeiras.

Os encontros foram diários, tendo a duração de quarenta e cinco minutos e totalizaram, incluíndo o primeiro dia, nove encontros. Algumas 
participantes do grupo desenvolveram a atividade durante a jornada de trabalho, pois reuniam-se, no grupo, enfermeiras procedentes de três diferentes turnos de trabalho (manhä, tarde e noite). Os temas discutidos foram determinados pelas participantes do grupo que pediam esclarecimentos à coordenadora, de forma direta e indireta. A coordenadora fornecia respostas ou devolvia as questões para reflexão, interferia quando as discuissões indicavam aspectos que requeriam reflexão, e sintetizava as questões discutidas. Durante um dos encontros foi aplicada a parte I do Inventário, que corresponde a questões relativas à ansiedade-estado, sendo focalizado o que haviam sentido com a experiência vivida no grupoo no dia anterior, pois, percebeu-se aumento da ansiedade diante de determinada situação.

No final dos encontros, parte I do IDATE (questionário de auto-avaliação) foi reaplicada, focalizando a questão inicial "Como você se sente em seu trabalho?". Foram programadas entrevistas com as enfermeiras e a coordenadora do grupo, nas quais os participantes indicaram as preocupações que haviam superado e aquelas que mereciam ser abordadas em outra oportunidade.

\section{Tratamento estatístico}

Para medir as diferenças entre o estado de ansiedade no início e no final dos trabalhos, utilizou-se o cálculo " $t$ " de Student, pelo método de diferenças diretas. Para medir as diferenças entre o traço de ansiedade e o estado de ansiedade usou-se o mesmo tratamento. Nesse cálculo transformou-se o escore obtido em um escore padrão normalizado "T", de Mcc Call, que corresponde a uma escala com média 50 e desvio padrão 10 , e permite comparar diferentes escalas (no caso, traço e estado de ansiedade), uma vez que transfere os dados para uma escala padronizada e nor-malizada (SPIELBERGER et alii, 1979).

\section{RESULTADOS}

Os dados obtidos serão apresentados através da descrição dos temas tratados durante os encontros, das características do grupo, as expectativas do grupo, sugestões e comentários e resultados do IDATE.

\section{Temas tratados}

Em geral, durante os encontros, o grupo teve como conduta aguardar as colegas que (por estarem trabalhando) não compareciam no horário previsto e ser predominantemente silencioso, sobretudo quando eraı dada por iniciada a atividade (o que era marcado pelo tempo ou número dos presentes).

No primeiro dia há silêncio, depois a busca de objetivos. Uma componente relata que a ausência de outras enfermeiras estava determinada pelos critérios impostos pela coordenadora dos trabalhos de grupo. Discorrem sobre como se sentem em serviço. Há expressão de sentimentos, 
referência às normas e organizaçã̉o. Não há identificação entre o que os componentes sentem (sentimentos) e as situações de trabalho.

A seguir o grupo tende a identificar que há diferenças entre fatos e os sentimentos que emergem relacionados aos fatos. Referem o fato de trabalhar sob pressão "de cima e de baixo". O tema é explorado por uma das componentes que primeiro relaciona a questão aos funcionários, depois "à estrutura maior": quanto ao que se sente diante desses fatos há manutenção das respostas sobre os fatos; após, descreve o que sente sem dar nome ao sentimento que a envolve, mencionando fatos com conteúdo de sentimentos de solidão e ansiedade, identificando-os depois, no plano intelectual. O grupo termina com alguns componentes dizendo que: "acaba quando o grupo está bom".

As intervenções ocorrem para esclarecer questões diretas sobre objetivos e para enfrentar a organização do coordenador; na realidade, indiretamente para questionar fatos e sentimentos: o que são pressões de "cima e de baixo", o que sentem diante do fato que expressam, qual o sentimento presente.

No segundo dia, a atmosfera é de risos, a identificação de nomes iguais entre as componentes de grupo e uma questão particular de uma das componentes. Há troca de lugares e referência a dores de cabeça de uma das componentes, ambiente poluido pelas fumantes; abrem janelas. Permanece a espera de uma das componentes e o silêncio. Contam o final da experiência do dia anterior a uma componente que não comparecera, a pedido desta. Retomam a discussão do dia anterior, aprofundando-a. Surge o tema "morte", seguido de normas de conduta profissional, aprendidos na Escola. Há contestação por parte de um dos membros que diz não sentir o mesmo - que mostra não submeter-se ao padrão imposto pelas normas. No entanto, o grupo fala de uma questão mais geral. Há alívio da tensão no grupo e uma certa identificação de que todas perpassam o sistema na situação grupal.

Terceiro dia - Chegam com livros. Os lugares variam. Há silêncio. A coordenadora, em face do desempenho de uma das participantes, avisa-a de que centralizará a discussão nas questões por ela levantadas sobre si mesma; explora então o que a participante sente e lhe pede para identificar o que sente e qual o seu sentimento. A experiência é acompanhada pelo grupo com atenção: - há silêncio, não há movimentos. Ao final da experiência a participante expressa sentir-se aliviada tendo durante o exercício, alternada a necessidade de parar e de continuar.

Quarto Dia - Há faltosas e expectativa do grupo de que elas cheguem. Aplica-se o IDATE (estado) pedindo que evoquem a experiência do dia anterior. Há silêncio; a seguir são feitas perguntas sobre os questionários e a coordenadora responde. Esta relaciona, então, aquela experiência com o que possam sentir na Instituição. Seguem então, com a questão relacionada com funcionários, questões que elas vivem como funcionárias; fazem relação do que se aprende para fazer com o paciente e o que se faz com a enfermeira no trabalho. 
Quinto Dia - Há silêncio. Há perguntas sem respostas. Fala-se sobre as que faltam (parte do grupo que faltara, na véspera, está presente) e uma das que haviam faltado, intercepta esse assunto, quando a coordenadora dele participa. Há receio do que está encoberto e o grupo tem participação nesse momento. Uma das componentes do grupo relata sua dificuldade em expressar-se, havendo manifestação igual de outra participante. Há o retorno ao objetivo não claro do trabalho de grupo e aos testes, expressado por uma das componentes, cuja participação do grupo foi, predominantemente, o silêncio. $O$ tema segue e, após algum tempo, uma componente refere que não haviam respondido à solicitação da colega que manifestara dificuldade em expressar-se, e retoma o tema "morte" que agora obtém participação de vários componentes. Há uma tendência em abandonar a questão "expressão de sentimentos" mas sua introdutora, nesse dia, termina o encontro, dizendo-se confusa.

Sexto Dia - Inicialmente há silêncio; a seguir as participantes expressam, à colega que faltara na véspera, que é irrecuperável o que fora tratado. A coordenadora faz uma reflexão sobre o que é irreversível, o irrecuperável e o que pode ser recuperado, e o relaciona à vivência que o grupo relatara sobre o interrelacionamento existente no serviço e sua estrutura.

Há menção às trocas no serviço, ao gostar ou não delas, às dificuldades e enriquecimento.

Sétimo Dia - As participantes retomam o tema do dia anterior, focalizando como é o grupo na Unidade de Trabalho. Seguem salientando o que ocorre em suas relações com os funcionários, como ocupar-se com eles quando não há pacientes, oferecê-los para outras clínicas. A submissão de alguns funcionários, o interesse de outros e o protesto ainda de outros. Não há respostas; surge a questão: "é difícil mudar" porém há quem diga que não sentiu dificuldade, a questão centra-se na pessoa. Há expressões: pode ser diferente, pode-se tentar. O grupo tenta manter-se reunido.

Oitavo Dia - Referem as participantes que uma componente do grupo está aniversariando. Falam da equipe multidisciplinar, os trabalhos isolados e da ansiedade que isso gera. A trocas freqüentes dos formandos da medicina, a comunicação interrompida de médicos na presença quando chega uma enfermeira. Há umas pessoas com mais dificuldade e outras com mais facilidade (na comunicação e no relacionamento). No início é mais difícil. Há mudanças de dois lados (referência a médicos e enfermeiras) "quando dão abertura, a gente chega mais neles". O IDATE é reaplicado na parte I (corresponde à ansiedade-estado) focalizando a mesma questão proposta no início dos trabalhos de grupo: "Como você se sente em seu trabalho?".

As caracteristicas apresentadas pelas enfermeiras que constituiam sujeito do estudo foram as seguintes: eram formadas entre os anos 1975 e 1982 havendo nos anos de 1981 e 1980 duas enfermeiras formadas 
nesses dois anos. As demais formaram-se em diferentes anos, podendo dizer-se que há uma enfermeira por turma de formatura, no espaço de oito anos.

Entre as enfermeiras, a formação em enfermagem pediátrica está concentrada nos anos 1975, 1976, 1977. Nos anos de 1981 e 1982 duas enfermeiras fizeram curso na área de Educação Psicomotora.

Uma, entre as dez, fez curso de especialização fora de área de enenfermagem pediátrica ou correlacionada. As demais, quatro enfermeiras, não têm formação especializada.

Observa-se também que o tempo de exercício na área distribui-se entre oito (8) e um (1) ano e meio de serviço, havendo concentração em torno de três a quatro anos. A concentração de enfermeiras com mais de quatro anos de serviço e a contratação daquelas que já trabalharam de três a quatro anos é respectivamente de formadas antes de 1978 e de formadas entre 1980 e 1982.

Os dados indicam que a admissão das enfermeiras, na área especializada, ocorre próxima à colação de grau.

Percebe-se que a formação especializada concentra-se nas enfermeiras formadas há mais tempo e trabalhando também há mais tempo na área.

Verifica-se, entre as questões formuladas, que sete, das dez enfermeiras, não têm experiência em tratamento psicológico. Em geral, 6 (seis) não faltamaoserviço, enquanto 3 (três) têm uma falta anual e uma (1) uma falta mensal. As faltas ocorrem por doenças tais como alergia, enxaqueca, hipertensão, pneumonia, sinusite, torcicolo, problema respiratório, gripe, acidente, licença gestação, hepatite, cólica, síndrome depressiva, hipertiroidismo.

As expectativas das enfermoiras quanto à atividade que desenvolveriam, foram, segundo suas próprias expressöes:

- A experiência e vivência dos componentes do grupo em relação à clientela e equipe multidisciplinar, bem como a atitude de cada em face de determinados problemas.

- Experiências do grupo perante as emoções e os sentimentos manifestados pelos participantes e manejados pelo grupo.

- Troca de informações em termos de sentimentos e emoções experimentados diariamente por nós, no nosso setor de trabalho. Discussão sobre aspectos que interferem no atendimento ao cliente.

- Oportunidade formal de reflexão sobre interação entre os membros da equipe de trabalho. Revisão de conceitos sobre habilidade em trabalhar com pessoas e manejar situações.

- Facilidade de expor com tranqüilidade, um sentimento ou percepção diante de um grupo. 
- Auxilio nas situações difícieis no relacionamento com criança, familia, enfermeira; interação de grupo e maturação.

- Troca de idéias, às vezes com o grupo de pessoas que podem entender como me sinto, o que já vivenciei na psicoterapia.

- Possibilidade de refletir sobre as dificuldades que normalmente se enfrentam e amadurecer pensamentos e atitudes em nosso benefício próprio e dos pacientes e seus familiares.

- Esperança de, através de experiências e da vivência de colegas, obter mais dados e ter mais "estrutura" para auxiliar os clientes em seu tratamento, assim como seus familiares.

- Esperança de que essa experiência traga subsídios para melhor se poder enfrentar as situações que se apresentam.

Após a atividade as enfermeiras consideram que:

- Haviam conhecido melhor as pessoas com quem trabalhavam, além daquelas que já conheciam, antes das reuniões de grupo.

- A vivência com o grupo possibilitara refletir sobre si mesma e isso facilitara a comunicação com grupos, mas que necessitariam refletir mais sobre esses aspectos.

- Ampliaram a comunicação com médicos, equipe de enfermagem e outras enfermeiras.

- Passaram a ter uma visão mais correta dos componentes das equipes multiprofissionais e dos componentes das outras sub- unidades, bem como do próprio trabalho. cionários.

- Foram facilitados o treinamento e a percepção do trabalho dos funcionários.

- Foi maior a sua compreensão das manifestações dos componentes de seu setor de trabalho e a forma com que se expressam.

- Houve diminuição da ansiedade depois que o grupo abordou e manejou as emoções que emergiam.

- A atividade deveria prosseguir.

- Foi muito rica a troca de experiências.

Se comparadas as expectativas com o trabalho desenvolvido pelo grupo e o que consideraram haver realizado, percebe-se uma relação entre os três aspectos, o que, possivelmente, contribuiu para os resultados obtidos pelo grupo na aplicação do IDATE. 
Escores de ansiedade medidas no grupó

O IDATE foi aplicado no inicio e no final dos encontros do grupo e após uma situação específica. As diferenças obtidas nessas situações são as que seguem:

QUADRO II

ESCORES DE ANSIEDADE E RESPECTTVO PADRAO T E MEDIAS

\begin{tabular}{|c|c|c|c|c|c|}
\hline \multirow{2}{*}{\multicolumn{2}{|c|}{$A$ - Traco }} & \multicolumn{4}{|c|}{ A - Dstado } \\
\hline & & \multicolumn{2}{|c|}{ Início } & \multicolumn{2}{|c|}{ Final } \\
\hline Excore & Padrăo T & Escore & Padrão $T$ & Escore & Padrato I \\
\hline 35 & 44 & 40 & 49 & 36 & 45 \\
\hline 39 & 48 & 43 & 52 & 35 & 43 \\
\hline 36 & 45 & 46 & 55 & 41 & 50 \\
\hline 33 & 40 & 31 & 37 & 30 & 35 \\
\hline 37 & 46 & 29 & 34 & 28 & 32 \\
\hline 41 & 51 & 59 & 65 & 30 & 35 \\
\hline 36 & 45 & 36 & 45 & 31 & 37 \\
\hline 31 & 37 & 44 & 53 & 29 & 34 \\
\hline 46 & 55 & 52 & 60 & 40 & 49 \\
\hline 31 & 37 & 44 & 53 & 41 & 50 \\
\hline $\bar{x} 36,5$ & 44,8 & 42,4 & 50,3 & 34,1 & 41 \\
\hline
\end{tabular}

QUADRO III

MADIA DAS DIFEREINÇAS, DESVIO PADRAO DAS DIFERERTCAS E VALOR \&t» DE STUDENT

\begin{tabular}{lccc}
\hline Diferengae estudadas & D & SD & «ts \\
\hline $\begin{array}{l}\text { Ansiedade-estado e ansiedade traço no } \\
\text { início da atividade }\end{array}$ & 5,5 & 2,83 & $1.94 *$ \\
\hline $\begin{array}{l}\text { Ansiedado-estado no inicio e no final } \\
\text { da atividade }\end{array}$ & 8,3 & 2,71 & $3.06^{* *}$ \\
\hline $\begin{array}{l}\text { Ansiedade-estado no final da atividade } \\
\text { e traço no inicio da atividade }\end{array}$ & 3,8 & 2,71 & 1.40 \\
\hline
\end{tabular}

* Significativa a 0,05

*** Significativa a 0,01

O grupo de enfermeiras apresentou diferenças significativas entre a ansiedade-estado, presente no início e no final dos encontros, indicando que houve redução no estado de ansiedade significativa a 0,01.

Igualmente, encontrou-se uma diferença significativa $(0,05)$ entre ansiedade-estado e ansiedade-traço no início dos trabalhos. 
No entanto, não foram obtidos resultados significativos entre as diferenças do traço de ansiedade e a ansiedade de estado no final da experiência, o que evidencia a redução da ansiedade-estado no final dos encontros de grupo.

Quanto à média da ansiedade-estado, durante uma situação intermediária do grupo, evidenciou-se aumento da ansiedade-estado entre as seis enfermeiras que compareceram ao encontro quando o IDATE foi reaplicado. Isso indica que a situação gera ansiedade, no caso relacionada às emoções desencadeadas por "enfrentamento".

\section{DISCUSSĀO}

A suposta ansiedade existente no grupo foi evidenciada pelo resultado obtido na aplicação do IDATE. Verificou-se, também, a redução do estado de ansiedade, após as sessões de grupo.

Examinadas as expectativas do grupo, os temas trabalhos, suas características e o resultado alcançado, percebe-se que o grupo tratou de encontrar soluções para as necessidades sentidas por suas componentes.

Uma questão, no entanto, não foi examinada e corresponde às diferenças que os componentes do grupo apresentam quanto a: tempo de graduação, formação na área especializada e tempo em que trabalham na área. Houve a tendência, entre os componentes, de examinar as questões de interação no serviço, das emoções decorrentes dessa interação, da compreensão das situações de trabalho que enfrentam.

$O$ fato pode estar relacionado às expectativas do grupo que visava esses objetivos, o que parece haver sido alcançado. O tema "o próprio grupo" aparece nas respostas dadas às experiências do grupo, quando os componentes referem a oportunidade de haver conhecido as colegas.

O referencial trabalhado durante as sessões parece haver ajudado as interações e a compreensão das situações de ansiedade enfrentadas no dia-a-dia e no próprio grupo. Por outro lado, percebe-se que o grupo adquiriu a capacidade de identificar e distinguir quando um fato desencadeava ansiedade ou outra emoção, a própria emoção e como enfrentá-la.

O achado é importante, uma vez que o pessoal de enfermagem enfrenta diariamente situações de tensão e ansiedade relacionadas ao ambiente de trabalho, determinadas por: morte e enfermidade, interações entre pacientes e familiares e entre as equipes, e estrutura administrativa. No caso em estudo as enfermeiras, ao mesmo tempo que exercem suas atividades com os clientes, têm responsabilidade para com seus funcionários e trabalham sob a coordenação de outras enfermeiras. $\mathrm{Pa}$ rece que experiências trocadas, no próprio grupo, beneficiam a execução das funções e a redução da ansiedade-estado, uma vez facilitada a compreensão dos fatores ligados à organização, ao próprio trabalho junto à clientela e às emoções sentidas. 


\section{CONCLUSOES}

A ansiedade que se supunha existir no grupo foi evidenciada através do IDATE, tendo sido verificada redução da ansiedade-estado significativa a nivel de 0,01 - entre o início e o final das reuniões do grupo. Logo, a experiência em dinâmica de grupo, que teve como referencial a proposta de SPIELBERGER (1981) "como conviver com tensão e ansiedade", evidenciou que quando as enfermeiras abordaram suas preocupações, identificaram emoções emergentes e, quando estas emoções emergiam, os recursos necessários para manejá-las eram identificados. Este fato parece haver ajudado as enfermeiras a reduzirem a ansiedade.

SCHMARCZEK, M. A study about a state-anxiety reduction through group dynamics. Rev. Esc. Enf. USP, São Paulo, 20(3):207-217, 1986.

State-anxiety was studied in a group of pediatric nurses who met to discuss their worries about work. State-anxiety was verified though the administration of State-Trait Anxiety Inventory of SPIELBERG; the results indicated a significant reduction of state-anxiety at the end of the sessions.

\section{BIBLIOGRAFIA}

1. GRAY, J.A. The neuropsychology of anxiety. Oxford. Clarendon Press, 1982.

2. HABER, V. \& RUNYON, V. Eetatfstica general. Bogotá, Fondo Educativo Interamericano, 1973.

3. SPIELBERGFR, C.D. Anxiety : current trends in theory and research. New York, Academic Press, 1976. Vol. 1.

4. SPIELBerger, C.D. Tensão ansiedade. São Paulo, Harbra, 1981.

5. SPIELBERGER, C.D.; GOURSUCH, R.L.; LUSHENE, R.E. Inventário de ansiedade, traco-estado: manual de psicologia aplicada. Rio de Janeiro, CEPA, 1979. 